EPJ Web of Conferences 59, 11003 (2013)

DOI: $10.1051 /$ epjconf/20135911003

(C) Owned by the authors, published by EDP Sciences, 2013

\title{
A specialized layering module for high rep-rate production of free standing HiPER targets
}

\author{
I. Aleksandrova ${ }^{1}$, A. Belolipetskiy ${ }^{2}$, E. Koresheva ${ }^{1}$, E. Koshelev ${ }^{1}$, E. Malinina ${ }^{2}$, \\ L. Mitina ${ }^{3}$, L. Panina ${ }^{4}$, V. Chtcherbakov ${ }^{1}$, M. Tolley $^{5}$, C. Edwards ${ }^{5}$ \\ and C. Spindloe ${ }^{5}$
}

${ }^{1}$ P. N. Lebedev Physical Institute, Russian Academy of Sciences, Moscow, Russia

${ }^{2}$ A.A. Dorodnitsin Computing Centre of Russian Academy of Sciences, Moscow, Russia,

${ }^{3}$ International Science and Technology Center, Moscow, Russia

${ }^{4}$ Prokhorov General Physics Institute, Russian Academy of Sciences, Moscow, Russia

${ }^{5}$ Science and Technology Facilities Council, Rutherford Appleton Laboratory, UK

\begin{abstract}
The target supply system is a necessary requirement for fueling a future energy source (reactor) with a high rep-rate: $0.1-10 \mathrm{~Hz}$. At the Lebedev Physical Institute (LPI), significant progress has been made in the technology based on rapid fuel layering inside moving free-standing targets that is referred to as FST (Free-Standing Targets) layering method. This allows creating a continuously or repeatable operating FST supply system, the development of which at LPI dates back to 1980s. Therefore, the LPI is in the position to propose the use of FST technologies for HiPER facility operation (conceptual design and prototype realization). Here we report on our most significant results on the development of a specialized layering module prototype for repeatable formation of HiPER free-standing cryogenic targets.
\end{abstract}

\section{INTRODUCTION}

A challenge that inertial fusion energy (IFE) research is facing is realizing the target delivery to the target chamber center at a rate of several Hz. Therefore, the IFE target fabrication technology is centered at methods that will scale to a high rep-rate and cost-effective target production. The targets must be freestanding, or un-mounted.

To meet these requirements, an approach to fuel layering based on using free-standing targets at each production step has been developed at LPI [1-4]. The FST layering is based on the conduction cooling of a batch of spherical targets moving inside the layering channel (LC, Fig. 1,2). The LC is a special insert into the layering module (LM), a certain portion of which must be at cryogenic temperatures. During FST layering, the target rotation results in a liquid layer symmetrization caused by its rolling in the LC. Because the targets move downward in a rapid succession - one after another, this results in a repeatable target injection into the test chamber (TC). The target characterization is based on microtomography methods of data processing [2-5] (Fig. 3). Using 100- projection micro-tomograph we have found that the inner surface roughness of the layer after FST layering is $0.15 \mu \mathrm{m} \mathrm{rms} \mathrm{for} \mathrm{mode} \mathrm{numbers} N=20$ 30 [2]. The TC is an interface unit in a modular assembly of the LM and injector (Fig. 4). This report describes in a condensed form the extension of the FST approach for design specifications of HiPERscale targets.

The conceptual baseline target design (Baseline Target-2) for the HiPER project is of two types [6]. The dimensions are as follows: (1) BT-2 is a 2.094-mm diameter compact polymer shell with a 3- $\mu \mathrm{m}$ thick wall. The solid layer thickness is $211 \mu \mathrm{m}$; and (2) BT-2a is a 2.046-mm diameter compact polymer

This is an Open Access article distributed under the terms of the Creative Commons Attribution License 2.0, which permits unrestricted use, distribution, and reproduction in any medium, provided the original work is properly cited. 


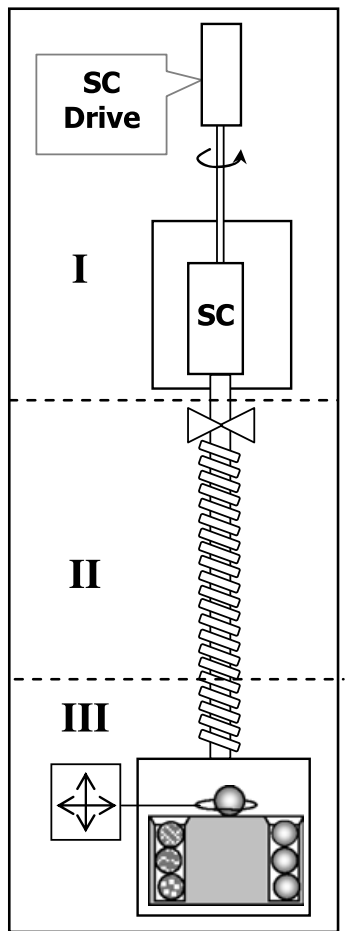

Figure 1. LM based on FST - technologies for high rep-rate production of cryogenic targets of HiPER-scale.
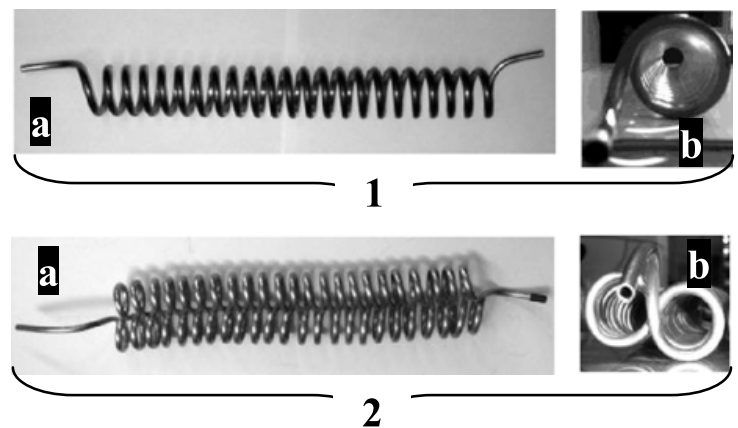

Figure 2. Layering channels of different geometry ( $\mathrm{a}$ - side view of the LC, $\mathrm{b}$ - top view of the LC). 1 - Singlespiral LC (mockup \#7): measured time $\tau_{\text {res }}=9.8 \mathrm{~s} ; 2$ - Double-spiral LC (mockup \#2): measured time $\tau_{\text {res }}=23.5 \mathrm{~s}$.

shell (3- $\mu \mathrm{m}$ thick also) having a DT-filled $\mathrm{CH}$ foam $(70 \mu \mathrm{m})$ on its inner surface. There is a $120 \mu \mathrm{m}$-thick solid layer of pure DT onto the inner surface of the foam.

\section{COMPUTATION}

The theoretical effort at LPI has focused on the creation of the FST Production Scheme Code of the HiPER targets response during the FST-formation cycle: fuel filling - fuel layering - target injection. Using the simulation results allows planning the experiments and studying the behavior of the targets in the FST layering module [4]. 


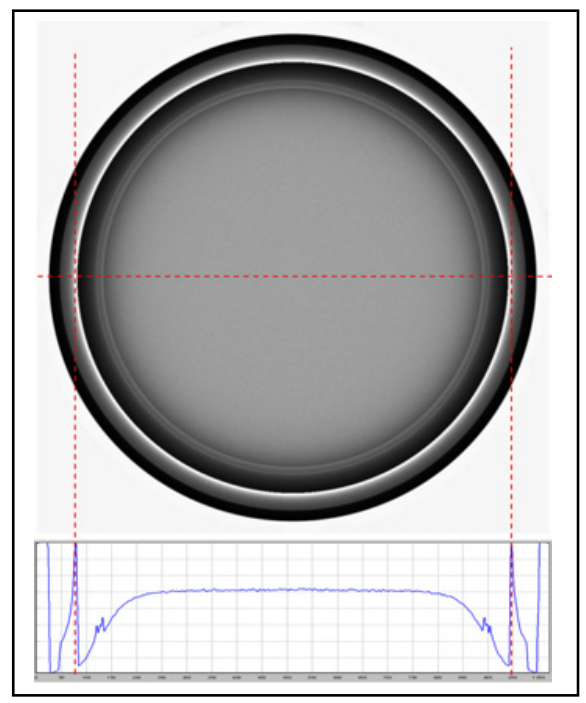

Figure 3. Simulated shadow image of HiPER target (at $A p=60^{\circ}$ ) and intensity profile of the image.

Input parameters for computation are as follows: (1) initial target configuration of HiPER- scale targets; (2) properties database at room and cryogenic temperatures; (3) thermal environment during the FST-formation cycle; (4) stress environment during the FST-formation cycle (transport process is target injection between fundamental system elements: shell container - layering module - test chamber). The output result is the computed optimization parameters (see Table 1) of the FST formation cycle for LM development for high rep-rate producing of HiPER cryogenic targets.

Table 1. Optimization parameters of the FST formation cycle for HiPER target.

\begin{tabular}{|l|c|c|}
\hline $\begin{array}{l}\text { Computed optimization } \\
\text { parameters }\end{array}$ & $\begin{array}{c}\text { BT-2 } \\
(\mathrm{D} 2-\mathrm{CH})\end{array}$ & $\begin{array}{c}\text { BT-2a } \\
(\mathrm{D} 2-\mathrm{CH})\end{array}$ \\
\hline Fill density & $97.0 \mathrm{mg} / \mathrm{cm}^{3}$ & $86.82 \mathrm{mg} / \mathrm{cm}^{3}$ \\
\hline Fill pressure at 300 K & $986.15 \mathrm{~atm}$ & $811.5 \mathrm{~atm}$ \\
\hline Fill time & $34.8 \mathrm{hrs}$ & $35.94 \mathrm{hrs}$ \\
\hline $\begin{array}{l}\text { Depressurization } \\
\text { temperature } \mathrm{T}_{\mathrm{d}}\end{array}$ & $31.1 \mathrm{~K}$ & $31.5 \mathrm{~K}$ \\
\hline $\begin{array}{l}\text { Fuel pressure in the } \\
\text { target at } \mathrm{T}_{\mathrm{d}}\end{array}$ & $5.35 \mathrm{~atm}$ & $5.84 \mathrm{~atm}$ \\
\hline $\begin{array}{l}\text { Temperature before } \\
\text { layering } \mathrm{T}_{\text {in }}\end{array}$ & $31.0 \mathrm{~K}$ & $31.0 \mathrm{~K}$ \\
\hline Pressure in the target at $\mathrm{T}_{\text {in }}$ & $5.34 \mathrm{~atm}$ & $5.34 \mathrm{~atm}$ \\
\hline FST layering time & $\sim 10 \mathrm{~s}$ & $\sim 7 \mathrm{~s}$ \\
\hline $\begin{array}{l}\text { Geometry of the } \\
\text { spiral LC }\end{array}$ & $\begin{array}{c}\text { angle }=5.7^{\circ}, \text { height }=55 \\
\mathrm{~cm}, \text { length }=5.51 \mathrm{~m}\end{array}$ \\
\hline Target residence time inside the LC & \multicolumn{2}{|c|}{$\sim 25 \mathrm{~s}$} \\
\hline
\end{tabular}

\section{EXPERIMENT AND DESIGN}

The goal of the experimental and design study is to facilitate the FST technology transfer from simulation into engineering stage. 
EPJ Web of Conferences

Table 2. Terminal velocity (computation \& exp.).

\begin{tabular}{|l|c|c|}
\hline $\begin{array}{l}\text { Parameters } \\
\text { of study }\end{array}$ & $\begin{array}{c}\text { BT-2 \& BT-2a } \\
\text { computation }\end{array}$ & $\begin{array}{c}\text { PAMS shells* } \\
\text { experiment }\end{array}$ \\
\hline Aspect ratio & 349 & 46.5 \\
\hline Shell thickness, $\mu \mathrm{m}$ & 3 & 20 \\
\hline$V_{\text {lim }}, \mathrm{m} / \mathrm{s}$ & 6.8 & $>3.43$ \\
\hline
\end{tabular}

$* /$ Experiment: Terminal velocity is given for a distance of gravity fall $=60 \mathrm{~cm}$.

The concept of the layering module based on the FST-technologies is shown in Fig. 1. It consists of the following basic units: shell container (SC), which is the intermediate unit between the fill system and the LM, layering channel (LC) for cryogenic layer formation by the FST layering method, and optical test chamber (TC), which is the intermediate unit between the LM and the delivery system.

The principle units of the prototype were manufactured and tested. The obtained experimental results allow supplementing the simulation and defining the baseline design of the FST layering module prototype for HiPER design specifications. The details of the study are presented in Ref. [4].

Among these units are: a set of spiral LC with different parameters (e.g., number of turns $\omega$, inclination angle $\alpha$, height L, and diameter D) and geometry (single spiral LC and double spiral LC) was manufactured from a $\mathrm{Cu}$ tube of $\varnothing 6.3 \times 0.75 \mathrm{~mm}$ (Fig. 2). The LC used in the experiments had parameters consistent with the following condition: the time $\left(\tau_{\text {res }}\right)$ of target residence inside the LC is greater than that for FST layering. In such experiments, polystyrene shells (made in LPI, Russia) and PAMS shells (made in STFC, UK) were used. The mockups testing revealed a considerable increase in the target residence time inside a double-spiral channel with respect to that for a single-spiral one. For example, for the single- and double- spiral channels with the same parameters (23 turns of a diameter of $38 \mathrm{~mm}$ and an inclination angle about 7 degrees, which gives the total length of $400 \mathrm{~mm}$ ) the target residence time was $9.8 \mathrm{~s}$ and $23.5 \mathrm{~s}$, respectively (see also cutline to Fig. 2). Notice, that the calculated layering time of HiPER target is about $10 \mathrm{~s}$ (see Table 1).

A crucial moment for DT fuel is the shell stability during impact after target injection into the TC (the most mechanical overloads are observed in the process of target landing onto the TC bottom). Therefore, the reduction of risks associated with the target damage during its injection requires special investigations to assess the shell stability. With this aim five PAMS shells were dropped down inside a 60 -cm-length vertical tube (ID $5 \mathrm{~mm}$ ). Note, that the height of the LC designed for the HiPER project is only $50 \mathrm{~cm}$. The experiments demonstrated no shell damage due to its landing onto the TC bottom.

Additionally, the simulation was performed to evaluate the shell stability during impact for both BT2 and BT-2a filled with DT [4]. The obtained results (terminal velocity $6.8 \mathrm{~m} / \mathrm{sec}$, see Table 2) showed that the outer polymer shell can be considered as a protection layer for a fragile cryogenic layer. This means that the current HiPER- scale targets have high-velocity stability.

The aforementioned concepts were implemented in the baseline design of the FST-LM prototype for HiPER targets (FST-LM-HiPER) [4], which also provides the description of the main elements of a prototype. The height of the LM is about $1.5 \mathrm{~m}$, the outer diameter (maximal) is about $45 \mathrm{~cm}$, and the liquid helium volume is about 5 liters. Our thermal and strength analysis has shown that the design of the FST-LM-HiPER satisfies the technical requirements and the requirements of the State Standards by these characteristics. The FST-LM-HiPER operation conditions: HiPER single shot and high-rep rate cryogenic capability (operation with a rate from $1 \mathrm{~Hz}$ ).

We plan to use 100-projections visual light micro-tomograph created at LPI [7] for precise characterization of the layering results at a single-step mode of the FST-LM-HiPER operation. Preliminary analysis has shown that the bright band on the HiPER target shadow image can be used for control of the fuel layer non-uniformity (NU) and surface roughness using the reverse algorithm BBP [2] developed at LPI. Figure 3 shows simulated shadow image of HiPER target (BT-2) at $60^{\circ}$ observation aperture. Numerical simulations are made for $500 \times 10^{6}$ rays with the help of 3D Ray Tracing code developed at LPI. 


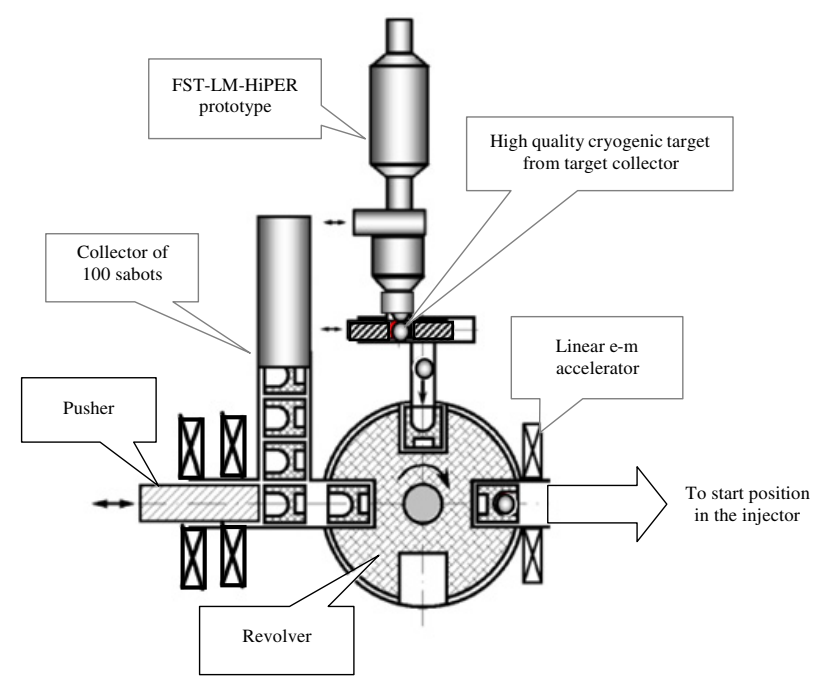

Figure 4. Modular assembly of high-rep rate FST-LM-HiPER prototype and cryogenic target injector.

We consider the Fourier holography of image recognition as a possible way to target on-line characterization [8] in the stage of rep-rate operation of the FST-LM-HiPER.

The concept of a full-scaled FST supply system has been developed. A design option of the system is shown in Fig. 4. The technical specifications for such a system are listed below:

1. Shell container (SC) holds from 100 to 200 fuel filled shells. The amount of the shells in the SC depends on the yield of high quality cryogenic targets during the FST-layering. In the case of $100 \%$ yield, the SC should contain 100 shells, for $50 \%$ yield the number increases to 200 shells, etc. The yield measurement is one of the main tasks of a study that is planned using the FST-LM-HiPER prototype.

2. SC transport from the fill system to the LM prototype proceeds at $300 \mathrm{~K}$.

3. FST-layering realization, i.e. fuel layering in free-standing shells, which move in a spiral layering channel

4. Sabot collector holds 100 sabots

5. Target collector holds 100 cryogenic targets

6. Cryogenic targets are injected under gravity from the target collector to the revolver

7. Sabot construction may contain elements from soft ferromagnetic material, which makes it possible to realize electro-magnetic delivery of the target- $\&$-sabot unit to a start position of the injector

8. Electro-magnetic delivery of the target-\&-sabot units to a start position of the injector proceeds with a high rep-rate (1-to-10 Hz).

This scheme operates in continuous regime of sabots loading from the collector to the revolver followed by rep-rated assembly of 100 target- $\&$-sabot assembly units and their delivery to a start position in the injector at a rate of $1-10 \mathrm{~Hz}$ (i.e. in "burst mode").

Choosing the above version of the LM \& injector assembly, all the components of the target supply system (LM, target-\&-sabot assembly device, injector) should operate synchronously. A control mechanism and special-purpose software should be developed to solve this problem.

\section{CONCLUSION}

In this report we have given an overview of the FST technologies for application to HiPER target fabrication and described possible ways of implementation of the latest developments in this area for engineering applications. 
The aim of the FST technologies is to demonstrate considerable benefits of using free-standing targets for realization of the production scheme with main stages: covering the shells with an outer protective layer, filling fuel, fuel layering inside a batch of moving free-standing shells, rep-rate assembly of target and sabot units and target injecting.

Using the FST technologies made it possible to find an original engineering solution for one of the key element of the target supply system (multitasking FST-LM-HiPER) intended for continuous fuel supply of the experiments on HiPER facility. The corresponding draft design of all the elements was developed including the information about potential production companies and cost analysis for the standard elements. The conditions of the FST-LM-HiPER operation are as follows: single shot and highrep rate cryogenic capability with a rate from $1 \mathrm{~Hz}$. As compared with a generally accepted approach, the FST-LM-HiPER based on using the moving free-standing targets allows minimizing the layering time and the tritiun inventory as well. Furthermore, we have developed a concept of modular assembly of the FST-LM-HiPER and target injector for fueling a power laser facility with a rate of $\geq 1 \mathrm{~Hz}$ (Fig. 4).

The current status of the FST technologies for HiPER project underlies the future research that focuses on the LM prototype manufacture, challenges and advances in HiPER target fabrication.

This work done under the International Science and Technology Center project \#3927 with the Science and Technology Facilities Council (STFC, UK) as a Partner.

\section{References}

[1] I. Aleksandrova, S. Bazdenkov, V. Chtcherbakov, E. Koresheva, I. Osipov, in: Inertial Fusion Science and Application, State of the art 2001 (2002)

[2] I. Aleksandrova, S. Bazdenkov, V. Chtcherbakov, E. Koresheva, E. Koshelev, I. Osipov, L. Yaguzinskiy, J. Phys. D: Appl. Phys. 37 (2004)

[3] E. Koresheva, I. Osipov, I. Aleksandrova, Laser and Particle Beams 23 (2005)

[4] I. Aleksandrova A. Belolipetskiy, V. Kalabuhov, E. Koresheva, E. Koshelev, A. Kutergin, A. Nikitenko, I. Osipov, L. Panina, A. Safronov, T. Timasheva, I. Timofeev, G. Usachev, V. Chtcherbakov, M. Tolley, C. Edwards, C. Spindloe. SPIE 8080 (2011)

[5] I. Aleksandrova, E. Koresheva, I. Osipov, S. Tolokonnikov, A. Belolipetskiy, L. Rivkis, G. Baranov, V. Listratov, V. Soloviev, I. Timofeev, G. Usachev, V. Veselov, L. Yaguzinskiy, Fusion Technology 38 (2000)

[6] S. Atzeni, A. Schiavi, C. Bellei, Phys. Plasmas 14 (2007); M. Tolley, F. ben Saïd, E. Koresheva, J.-P. Perin, J. M. Perlado, G. Schaumann, G. Schurtz, C. Spindloe, SPIE 8080 (2011)

[7] E. Koresheva, I. Osipov, I. Aleksandrova, A. Nikitenko, S. Tolokonnikov, V. Listratov, I. Timofeev, A. Kupriyashin, V. Leonov, E. Koshelev, G. Baranov, G. Usachev, T. Timasheva, A. Gromov, J. Russian Laser Research, 28 N2 (2007)

[8] E. Koresheva, A. Nikitenko, I. Aleksandrova, S. Bazdenkov, A. Belolipetskiy, V. Chtcherbakov, I. Osipov, Nuclear Fusion 46, 890, 2006 